\title{
Land Valuation with Analytical Hierarchy Process and Regression Method in Grogol Sub-District, Sukoharjo District
}

\author{
Arga Fondra Oksaping1 ${ }^{1}$, Djurdjani², Prijono Nugroho ${ }^{2}$ \\ ${ }_{1}^{1}$ Magister Teknik Geomatika, Departemen Teknik Geodesi, Fakultas Teknik, Universitas Gadjah Mada, Indonesia \\ 2 Departemen Teknik Geodesi, Fakultas Teknik, Universitas Gadjah Mada, Indonesia
}

\section{Article History:}

Received 12 November 2018

Received in revised form 30 January 2019

Accepted 23 May 2019

Available online 28 June 2019

\section{Keywords: \\ Penilaian tanah, Faktor nilai tanah, bobot nilai tanah, Analytical Hierarchy Process (AHP), Regresi}

\section{Corresponding Author:}

Arga Fondra Oksaping

Email: argafondra01@gmail.com

\begin{abstract}
Land valuation is a set of processes to determine the value of land plot. In conducting land valuation, it is necessary to considering the factors that affect values of land which caused land values in each region to be different. In order to objective land valuation, it is necessary to analyze the magnitude of factors that influencing the value of land. The Analytical Hierarchy Process (AHP) method is used in this study to analyzing the magnitude value of land in Grogol Sub-district, Sukoharjo District. Factors used are field distance to CBD, field distance to road, field distance to river, field distance to health facilities, field distance to educational facilities, and land use. The data used in this study were obtined from Sukoharjo Land Office, which is the data of sale and purchase transaction in Grogol Sub-district, Sukoharjo District, totaling 178 data from January to December 2016. Transaction data and factors influence land value are analyzed by Regression Method to obtain the best value model in Grogol Subdistrict, Sukoharjo District.
\end{abstract}

(C) Author(s) 2019. This is an open access article under the Creative Commons Attribution-ShareAlike 4.0 International License (CC BY-SA 4.0).

\section{Pendahuluan}

Badan Pertanahan Nasional sesuai dengan Peraturan Presiden No 20 Tahun 2015 merupakan Lembaga Pemerintahan yang mempunyai tugas melaksanakan tugas pemerintahan di bidang pertanahan, termasuk di dalamnya perumusan dan pelaksanaan kebijakan di bidang survei, pengukuran, dan pemetaan (Pasal 3). Persoalan yang terjadi di lapangan terkait dengan pemetaan tematik nilai tanah adalah belum adanya sistem penilaian tanah yang mencerminkan nilai atau harga pasar yang nyata.

Metode penilaian tanah yang digunakan oleh Badan Pertanahan Nasional untuk pembuatan Peta Nilai Tanah adalah metode penilaian tanah secara massal untuk tanah yang belum terbangun atau tanah yang dapat dipertimbangkan sebagai tanah kosong dengan menggunakan prosedur perbandingan penjualan (sales comparison). Dengan metode ini cara penentuan nilai tanah dilakukan dengan membandingkan antara objek yang akan dinilai dengan objek lain yang sejenis di sekitarnya yang telah diketahui nilai jualnya dengan memberikan penyesuaian atas perbedaan kondisi yang diperbandingkan yang dipandang perlu. Besarnya nilai yang diberikan untuk penyesuaian dalam disiplin ilmu penilaian dikenal sebagai nilai adjustment (Siregar, 2012) Penentuan variabel atau faktor-faktor yang diperbandingkan dan besarnya nilai adjustment harus berdasarkan kepada kenyataan, data dan fakta di lapangan dan dianalisis terlebih dahulu, sehingga di setiap wilayah dapat berbeda.

Kawasan Solo baru yang merupakan bagian dari Kecamatan Grogol Kabupaten Sukoharjo pada awalnya ditujukan untuk membentuk kawasan perumahan dengan sistem hunian berimbang, guna menampung luapan penduduk dari Kota Surakarta. Namun seiring dengan perkembangan waktu, Kawasan Solo Baru tidak lagi hanya memiliki fungsi sebagai daerah perumahan namun muncul pula fungsi-fungsi lain yang lebih kompleks seperti fungsi perdagangan, jasa ataupun industri (Arifia, 2016). Hal ini akan menimbulkan perubahan pola nilai tanah secara signifikan di kawasan tersebut.

Dengan adanya perubahan pola nilai tanah di suatu kawasan seperti di kecamatan Grogol, Kabupaten 
Sukoharjo mendorong dilakukan penilaian tanah terbaru, tetapi pada prakteknya seorang penilai cenderung menyederhanakan proses penilaian yang seharusnya didasarkan pada data dan fakta di lapangan serta memperhitungkan beberapa variabel yang mempengaruhi nilai tanah tersebut. Tingkat pengetahuan dan pengalaman seorang penilai berpengaruh terhadap hasil penilaian tanah. Kurangnya pengetahuan dan pengalaman akan menghasilkan nilai tanah yang kurang objektif. Unsur subjektifitas dari seorang penilai akan berpengaruh terhadap nilai tanah yang dihasilkan. Salah satu cara yang dapat digunakan untuk meminimalisir unsur subjektifitas dalam penilaian tanah adalah dengan pendekatan metode Analytical Hierarchy Process (AHP) dimana metode ini dapat merubah data yang sifatnya kualitatif menjadi kuantitatif (Marimin, 2004).

Dalam menyelesaikan persoalan dengan AHP, ada beberapa prinsip dasar yang harus dipahami antara lain Dekomposisi, (mendefinisikan permasalahan dan memecah persoalan yang utuh menjadi unsur-unsurnya), Comparative Judgement 9membuat penilaian tentang kepentingan relatif dalam bentuk matriks Pairwise Comparison), Synthesis of Priority (melakukan sintesis prioritas dari setiap matriks pairwise),dan Logical Consistency (obyek-obyek yang serupa dapat dikelompokan sesuai keseragaman dan relevansinya, dan tingkat hubungan antara obyek-obyek yang didasarkan pada kriteria tertentu) (Marimin, 2004).

Regresi merupakan model perhitungan matematis yang dapat memperkirakan nilai tanah untuk menghitung rasio antara harga tanah untuk jenis tanah yang berbeda. Prosedur ini dapat cukup berharga ketika ada beberapa penjualan perbandingan berpasangan. Rasio harga antara tanah jenis dapat berubah karena perubahan profitabilitas dari berbagai jenis tanah, sehingga menyesuaikan rasio harga antara jenis tanah harus dilakukan terutama ketika harga berubah dengan cepat (Wilson, DKK, 2014).

Maksud dan tujuan penelitian ini adalah melakukan penilaian tanah di Kecamatan Grogol Kabupaten Sukoharjo agar dapat menggambarkan nilai tanah yang sebenarnya dengan metode Analytical Hierarchy Process (AHP) dan Regresi di Kecamatan Grogol, Kabupaten Sukoharjo.

\section{Data dan Metodologi}

\subsection{Data dan Lokasi}

Data yang digunakan dalam penelitian ini adalah

- Peta bidang tanah dan jaringan jalan Kecamatan Grogol, Kabupaten Sukoharjo, format shapefile (shp), sumber peta di dapat dari Badan Pertanahan Nasional Kabupaten Sukoharjo.

- Peta tata guna lahan dan sungai Kecamatan Grogol, Kabupaten Sukoharjo format shapefile (shp), sumber peta di dapat dari Bapedda Kabupaten Sukoharjo.
- Data transaksi jual beli tanah di Kecamatan Grogol Kabupaten Sukoharjo dari Badan Pertanahan Kabupaten Sukoharjo (178 data transaksi)

- Data lokasi CBD, Fasilitas kesehatan (Rumah Sakit dan Puskesmas), dan sarana pendidikan (SD, SMP,SMA, Universitas/Akademi) yang ada di kecamatan Grogol, Kabupaten Sukoharjo.

Lokasi penelitian ini dilakukan di Kecamatan Grogol, Kabupaten Sukoharjo.

\subsection{Metodologi}

Penelitian akan dilakukan sesuai dengan yang ditunjukkan diagram alir pada Gambar 2.1 dapat dijelaskan sebagai berikut: faktor yang mempengaruhi nilai tanah terdiri dari jarak bidang terhadap CBD, jarak bidang ke jalan, jarak terhadap fasilitas kesehatan,fasilitas pendidikan, dan jenis penggunaan lahan. Penentuan nilai bobot setiap faktor dalam pengaruh terhadap nilai tanah diperoleh dengan metode $A H P$. Demikian pula untuk bobot sub kriteria.

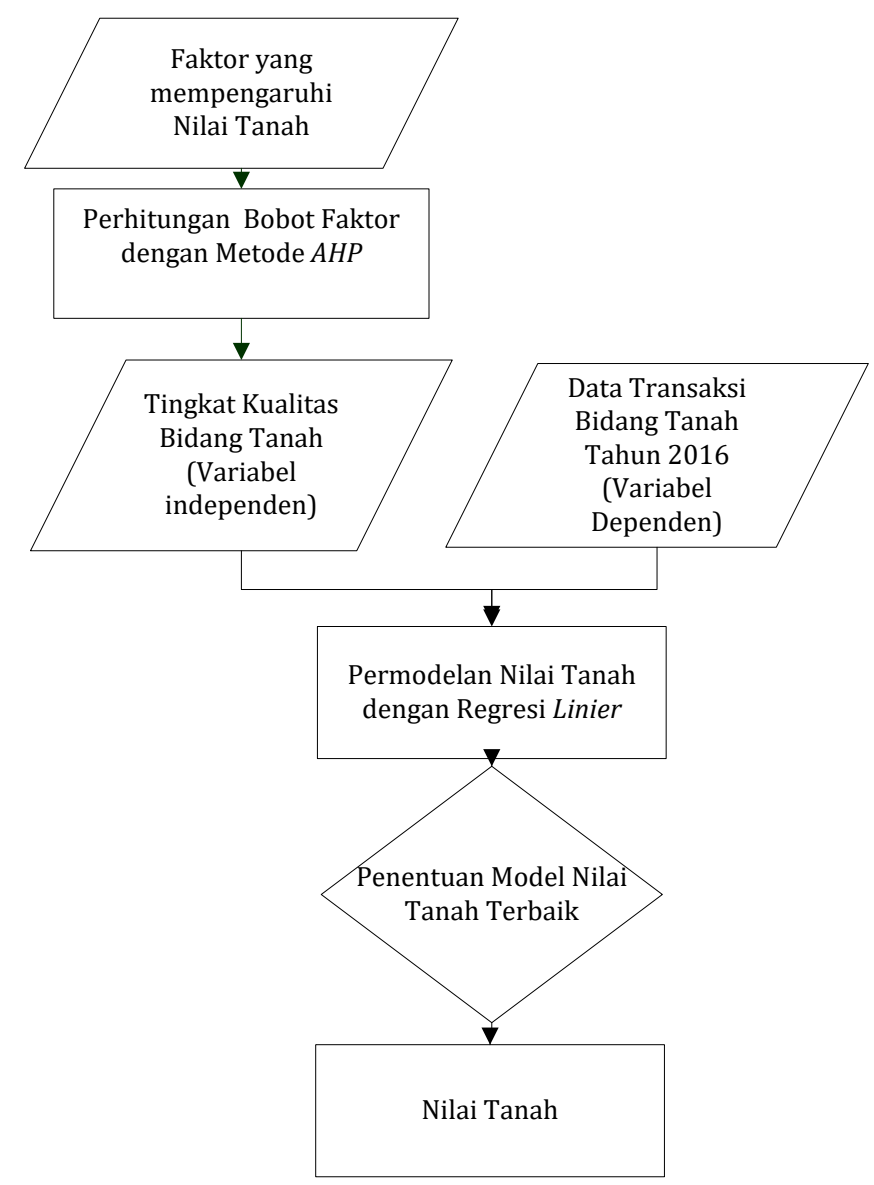

Gambar 2.1. Bagan Alir penelitian

Setelah semua faktor sudah ditentukan nilai bobotnya difungsikan sebagai variabel independen (variabel $\mathrm{x}$ ) sedangkan harga jual tanah setelah dilakukan koreksi sebagai variabel dependen (variabel y). untuk 
mendapatkan model nilai tanah dari Regresi, setelah melalui uji kriteria asumsi klasik dan uji kriteria statistik akan mendapatkan model tanah yang terbaik yang digunakan untuk membuat pola nilai tanah di Kecamatan Grogol kabupaten Sukoharjo.

\section{Hasil dan Pembahasan}

\subsection{Hasil pembobobotan}

Metode Analytical Hierarchy Process (AHP) merupakan salah satu metode untuk menentukan besarnya bobot di masing masing faktor yang mempengaruhi nilai tanah di Kecamatan Grogol Kabupaten Sukoharjo yang melibatkan 4 orang responden dari Badan Pertanahan Nasional dan Balai Diklat Keuangan yang menurut penulis memiliki pengalaman dalam pekerjaan penilaian, Besarnya bobot untuk masing masing faktor yang mempengaruhi nilai tanah di Kecamatan Grogol, Kabupaten Sukoharjo ditunjukkan dalam Gambar 3.1.

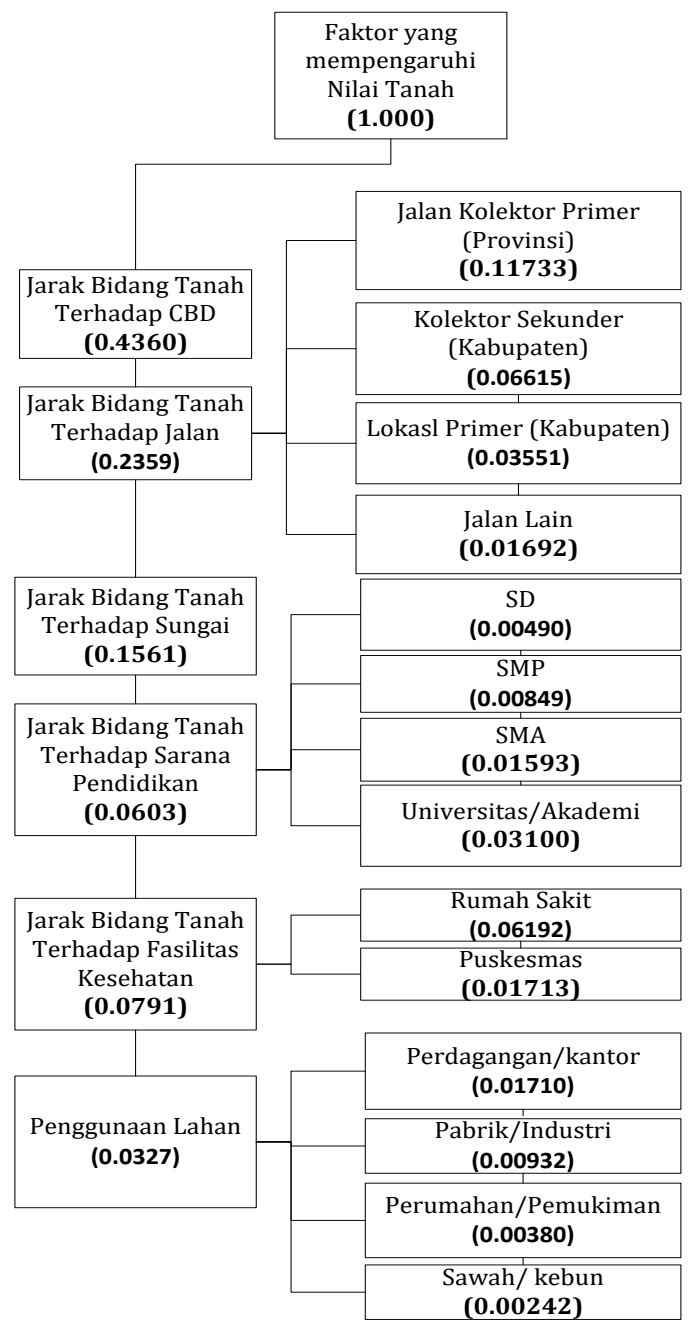

Gambar 3.1. Hasil perhitungan AHP Responden
Nilai bobot dari masing masing faktor diatas difungsikan sebagai variabel independen dengan melihat Nilai bobot masing-masing kriteria penentu nilai tanah disintesiskan/dipadukan dengan nilai skor tiap bidang tanah akan dihasilkan nilai tingkat kualitas bidang tanah pada masing-masing kriteria per bidang tanah. informasi harga transaksi dilakukan pemodelan dengan regresi berganda dengan menerapkan empat bentuk model fungsional regresi, yaitu model linier (lin-lin), semilog (linlog), semilog (log-lin) dan logaritma (log-log).

Dari hasil permodelan nilai tanah dari 4 metode regresi dilakukan beberapa pengujian meliputi uji statistik (uji T, uji $F$, Uji $R^{2}$ ) dan uji asumsi klasik (Multikolinieritas, dan Heteroskedastisitas)

\subsection{Uji Statistik}

Uji kriteria statistik dilakukan untuk mengetahui kriteria statistik dari model yang dihasilkan dari proses regresi yang meliputi uji signifikansi parameter dengan melakukan uji t parsial, uji signifikansi regresi dengan melakukan uji F dan uji koefisien determinasi $\left(\mathrm{R}^{2}\right)$.

\subsubsection{Uji t parsial}

Uji t parsial dilakukan untuk melihat apakah setiap variabel independen berpengaruh signifikan terhadap variabel dependen. Hasil dari uji t parsial dapat dilihat di Tabel 3.1 .

Jika ${ }^{\mathrm{t}}$ hitung $>\mathrm{t}$ tabel, atau masing masing variabel bebas independen berpengaruh signifikan terhadap variabel tak bebas dependen. Dengan derajat kebebasan (df) $=\mathrm{n}-\mathrm{k}-1$ $=178-13-1=164$ dan tingkat kepercayaan 95\%, diperoleh $\boldsymbol{t}_{\text {tabel }}=1.97453$

$\underline{\text { Tabel 3.1. Hasil uji t dari masing masing model nilai tanah }}$

\section{NO Variabel Model Lin-Lin Model Lin-Log}

\begin{tabular}{cccccc}
\hline & & $\begin{array}{l}\text { T } \\
\text { hitung }\end{array}$ & Sig & $\begin{array}{l}\text { T } \\
\text { hitung }\end{array}$ & Sig \\
\hline 1 & (Constant) & 0.030 & tidak & 4.403 & ya \\
2 & Nilai_CBD & 3.011 & ya & 2.695 & ya \\
3 & Nilai_JL_KP & 2.174 & ya & 3.718 & ya \\
4 & Nilai_JL_KS & -1.622 & tidak & 0.633 & tidak \\
5 & Nilai_JL_LP & 0.509 & tidak & -1.023 & tidak \\
6 & Nilai_Jlain & 0.440 & tidak & -0.617 & tidak \\
7 & Nilai_Sungai & -0.270 & tidak & 3.608 & ya \\
8 & Nilai_PUS & 5.737 & ya & 4.035 & ya \\
9 & Nilai_RS & 2.202 & ya & 1.241 & tidak \\
10 & Nilai_SD & 2.719 & ya & 2.626 & ya \\
11 & Nilai_SMP & 0.315 & tidak & -0.028 & tidak \\
12 & Nilai_SMA & 0.618 & tidak & 0.462 & tidak \\
13 & Nilai_UNV & 0.660 & tidak & 1.140 & tidak \\
14 & nilai_PL & 0.764 & tidak & 0.279 & tidak \\
\hline
\end{tabular}


Tabel 3.1. Hasil uji t dari masing masing model nilai tanah (lanjutan)

\begin{tabular}{|c|c|c|c|c|c|}
\hline \multirow{2}{*}{ NO } & \multirow{2}{*}{ Variabel } & \multicolumn{2}{|c|}{ Model Log-Lin } & \multicolumn{2}{|c|}{ Model Log-Log } \\
\hline & & $\begin{array}{c}\mathrm{T} \\
\text { hitung }\end{array}$ & Sig & $\begin{array}{c}\mathrm{T} \\
\text { hitung }\end{array}$ & Sig \\
\hline 1 & (Constant) & 22.249 & yа & 15.207 & yа \\
\hline 2 & Nilai_CBD & 3.677 & уа & 3.015 & yа \\
\hline 3 & Nilai_JL_KP & 2.462 & уа & 5.423 & ya \\
\hline 4 & Nilai_JL_KS & -1.711 & tidak & -0.568 & tidak \\
\hline 5 & Nilai_JL_LP & 0.748 & tidak & 0.341 & tidak \\
\hline 6 & Nilai_Jlain & 1.366 & tidak & 1.014 & tidak \\
\hline 7 & Nilai_Sungai & 1.390 & tidak & 5.229 & ya \\
\hline 8 & Nilai_PUS & 4.970 & уа & 3.488 & yа \\
\hline 9 & Nilai_RS & 1.130 & tidak & 0.886 & tidak \\
\hline 10 & Nilai_SD & 3.188 & ya & 5.190 & ya \\
\hline 11 & Nilai_SMP & 0.949 & tidak & 0.746 & tidak \\
\hline 12 & Nilai_SMA & 0.366 & tidak & 0.501 & tidak \\
\hline 13 & Nilai_UNV & 2.007 & ya & 3.677 & ya \\
\hline 14 & nilai_PL & 2.825 & уа & 1.946 & tidak \\
\hline
\end{tabular}

Pada tabel diatas diketahui bahwa ada beberapa variabel independen yang tidak berpengaruh signifikan terhadap variabel dependen karena ${ }^{\mathrm{t}}$ hitung $<{ }^{\mathrm{t}}$ tabel, pada model lin-lin variabel yang tidak berpengaruh signifikan adalah jarak bidang terhadap jalan kolektor sekunder, jarak bidang terhadap jalan lokal primer, jarak bidang terhadap jalan lain, jarak bidang terhadap sungai, jarak bidang terhadap SMP, jarak bidang terhadap SMP, jarak bidang terhadap SMA, jarak bidang terhadap Universitas/Akademi, dan penggunaan lahan. Pada model lin-log variabel yang tidak berpengaruh signifikan adalah jarak bidang terhadap jalan kolektor sekunder, jarak bidang terhadap jalan lokal primer, jarak bidang terhadap jalan lain, jarak bidang terhadap rumah sakit, jarak bidang terhadap SMP, jarak bidang terhadap SMP, jarak bidang terhadap SMA, jarak bidang terhadap Universitas /Akademi, dan penggunaan lahan. Pada model log-lin variabel yang tidak berpengaruh signifikan adalah jarak bidang terhadap jalan kolektor sekunder, jarak bidang terhadap jarak bidang terhadap jalan lokal primer, jarak bidang terhadap jalan lain, jarak bidang terhadap sungai, jarak bidang terhadap SMP, jarak bidang terhadap SMP, jarak bidang terhadap SMA.. Pada model $\log$-log variabel yang todak berpengaruh signifikan adalah variabel jarak bidang terhadap jalan kolektor sekunder, jarak bidang terhadap jarak bidang terhadap jalan lokal primer, jarak bidang terhadap jalan lain, jarak bidang terhadap SMP, jarak bidang terhadap SMA. Dan penggunaan lahan.

\subsubsection{Uji F}

Uji F dilakukan untuk mengetahui apakah variabel independen secara bersama sama berpengaruh terhadap variabel dependen. Hasil dari uji F dapat dilihat di Tabel 3.2 .

kriteria yang ditetapkan adalah jika $F_{\text {hitung }}>F_{\text {tabe }}$ l maka berarti variabel bebas secara bersama-sama berpengaruh secara signifikan terhadap variabel tak bebas, Dari hasil penelitian ini diketahui nilai $\mathrm{F}_{\text {tabel }}$ untuk $\alpha=0,05, \mathrm{k}-1, \mathrm{n}-\mathrm{k}$ adalah (13-1), (178-13)=12, $165 \rightarrow(1.81) . \rightarrow($ tabel F $)$

Tabel 3.2. Hasil uji F model nilai tanah

\begin{tabular}{cccc}
\hline $\begin{array}{c}\text { Model } \\
\text { Lin-Lin }\end{array}$ & $\begin{array}{c}\text { Model } \\
\text { Lin-Log }\end{array}$ & $\begin{array}{c}\text { Model } \\
\text { Log-Lin }\end{array}$ & $\begin{array}{c}\text { Model } \\
\text { Log-Log }\end{array}$ \\
\hline F Hitung & F Hitung & F Hitung & F Hitung \\
\hline 7.676 & 14.816 & 8.024 & 27.464 \\
\hline
\end{tabular}

Nilai F-hitung untuk semua model regresi lebih besar dari nilai $\mathrm{F}$-tabel, sehingga dapat disimpulkan bahwa seluruh variabel independen yang digunakan dalam model secara bersama-sama berpengaruh signifikan terhadap variabel dependen.

\subsubsection{Uji Koefisien $\mathrm{R}^{2}$}

Uji koefisien $\mathrm{R}^{2}$ adalah untuk mengetahui seberapa besar pengaruh variabel dependen terhadap variabel independen. Hasil dari uji koefisien $\mathrm{R}^{2}$ dapat dilihat pada Tabel 3.3.

Tabel 3.3. Hasil koefisien $\mathrm{R}^{2}$ model nilai tanah

\begin{tabular}{cccc}
\hline $\begin{array}{c}\text { Model } \\
\text { Lin-Lin } \\
\left(\mathbf{R}^{\mathbf{2}}\right)\end{array}$ & $\begin{array}{c}\text { Model } \\
\text { Lin-Log } \\
\left(\mathbf{R}^{\mathbf{2}}\right)\end{array}$ & $\begin{array}{c}\text { Model } \\
\text { Log-Lin } \\
\left(\mathbf{R}^{\mathbf{2}}\right)\end{array}$ & $\begin{array}{c}\text { Model } \\
\text { Log-Log } \\
\left(\mathbf{R}^{2}\right)\end{array}$ \\
\hline 0.329 & 0.504 & 0.340 & 0.660 \\
\hline
\end{tabular}

Dari nilai koefisien $\mathrm{R}^{2}$, model yang terbaik adalah model log-log yang memiliki nilai $\mathrm{R}^{2} 66 \%$, artinya perubahan nilai tanah dipengaruhi oleh variabel independennya sebesar $66 \%$, sedangkan $34 \%$ dipengaruhi oleh variabel lain yang tidak diteliti.

\subsection{Uji Asumsi klasik}

Pada penelitian ini uji asumsi klasik yang digunakan adalah mengetahui gejala multikolinieritas dan heteroskedastisitas

\subsubsection{Uji multikolinieritas}

Uji multikolinieritas dilakukan untuk melihat korelesai antar variabel independen, seperti terlihat dalam Tabel 3.4 
Tabel 3.4. Hasil uji multikolinieritas

\begin{tabular}{|c|c|c|c|c|}
\hline \multirow[t]{2}{*}{ Variabel } & \multicolumn{2}{|l|}{$\begin{array}{l}\text { Model Lin- } \\
\text { Lin }\end{array}$} & \multicolumn{2}{|l|}{$\begin{array}{l}\text { Model Lin- } \\
\text { Log }\end{array}$} \\
\hline & Tole rance & VIF & Tole rance & VIF \\
\hline Nilai_CBD & 0.595 & 1.682 & 0.261 & 3.826 \\
\hline Nilai_JL_KP & 0.928 & 1.078 & 0.391 & 2.559 \\
\hline Nilai_JL_KS & 0.76 & 1.316 & 0.59 & 1.695 \\
\hline Nilai_JL_LP & 0.903 & 1.108 & 0.709 & 1.41 \\
\hline Nilai_Jlain & 0.933 & 1.072 & 0.895 & 1.117 \\
\hline Nilai_Sungai & 0.721 & 1.387 & 0.376 & 2.658 \\
\hline Nilai_PUS & 0.737 & 1.358 & 0.556 & 1.8 \\
\hline Nilai_RS & 0.546 & 1.832 & 0.335 & 2.988 \\
\hline Nilai_SD & 0.93 & 1.075 & 0.674 & 1.484 \\
\hline Nilai_SMP & 0.859 & 1.164 & 0.558 & 1.792 \\
\hline Nilai_SMA & 0.606 & 1.65 & 0.29 & 3.451 \\
\hline Nilai_UNV & 0.59 & 1.696 & 0.356 & 2.811 \\
\hline nilai_PL & 0.863 & 1.159 & 0.821 & 1.218 \\
\hline
\end{tabular}

Tabel 3.4. Hasil uji multikolinieritas (Lanjutan)

\begin{tabular}{lllll}
\hline Variabel & $\begin{array}{l}\text { Model } \\
\text { Log-Lin }\end{array}$ & & $\begin{array}{l}\text { Model } \\
\text { Log-Log }\end{array}$ \\
& & & Tole \\
rance & VIF & $\begin{array}{l}\text { Tole } \\
\text { rance }\end{array}$ & VIF \\
\cline { 2 - 5 } Nilai_CBD & 0.595 & 1.682 & 0.261 & 3.826 \\
Nilai_JL_KP & 0.928 & 1.078 & 0.391 & 2.559 \\
Nilai_JL_KS & 0.76 & 1.316 & 0.59 & 1.695 \\
Nilai_JL_LP & 0.903 & 1.108 & 0.709 & 1.41 \\
Nilai_Jlain & 0.933 & 1.072 & 0.895 & 1.117 \\
Nilai_Sungai & 0.721 & 1.387 & 0.376 & 2.658 \\
Nilai_PUS & 0.737 & 1.358 & 0.556 & 1.8 \\
Nilai_RS & 0.546 & 1.832 & 0.335 & 2.988 \\
Nilai_SD & 0.93 & 1.075 & 0.674 & 1.484 \\
Nilai_SMP & 0.859 & 1.164 & 0.558 & 1.792 \\
Nilai_SMA & 0.606 & 1.65 & 0.29 & 3.451 \\
Nilai_UNV & 0.59 & 1.696 & 0.356 & 2.811 \\
nilai_PL & 0.863 & 1.159 & 0.821 & 1.218 \\
\hline
\end{tabular}

Berdasarkan Tabel 3.4, keempat model regresi multikolinieritas yang terjadi adalah berderajat rendah karena nilai $\mathrm{VIF}<10$, dan nilai toleransi $>0.10$ maka tidak terjadi korelasi antara variabel independen satu dan lainnya.

\subsubsection{Uji Heteroskedastisitas}

Uji Heteroskedastisitas dilakukan untuk menguji terjadinya perbedaan variance dari nilai residual dari suatu data ke data lainnya. Hasil uji Heteroskedastisitas dapat dilihat dari gambar scatterplots Gambar 3.2, Gambar 3.3, Gambar 3.4, dan Gambar 3.5.

Scatterplot

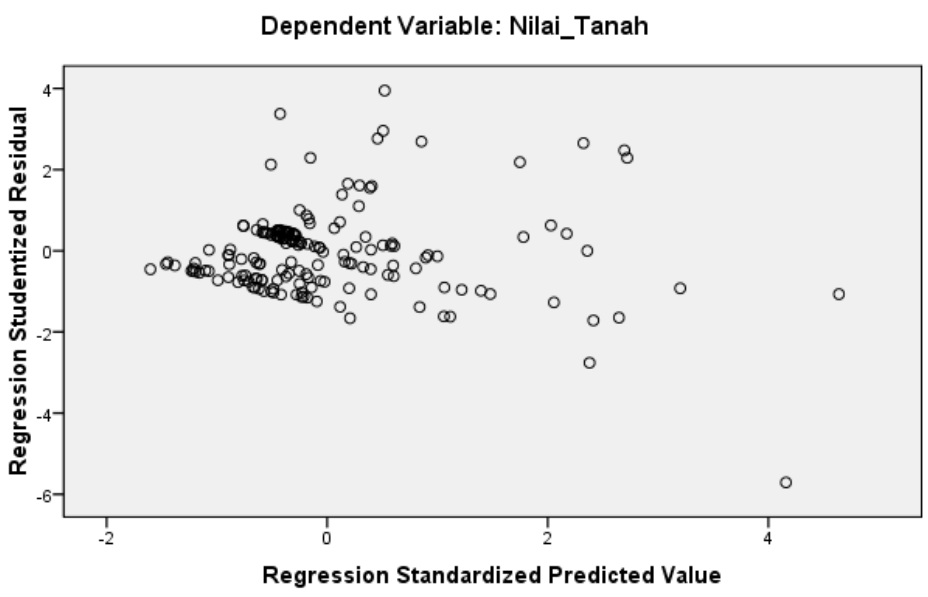

Gambar 3.2. Scatterplots Lin lin model

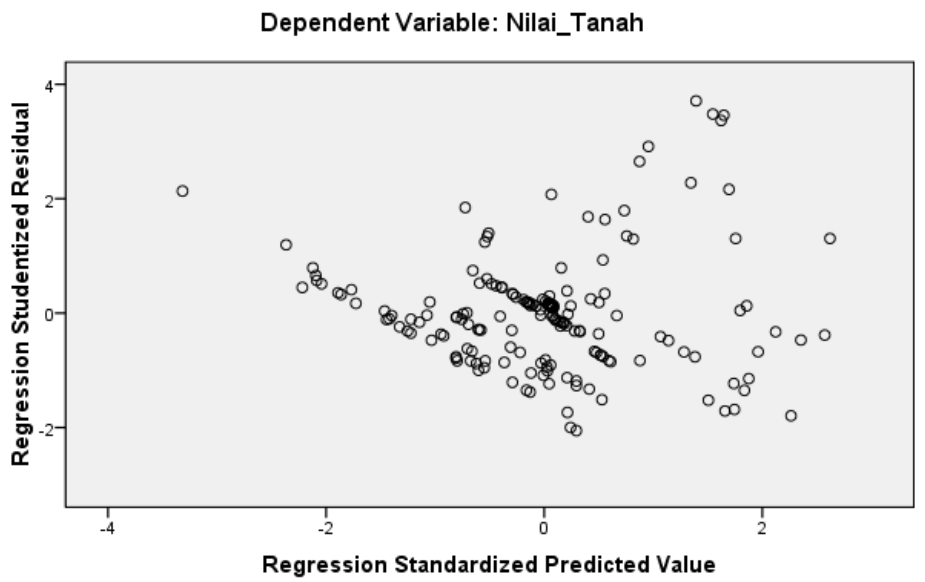

Gambar 3.3. Scatterplots Lin log model

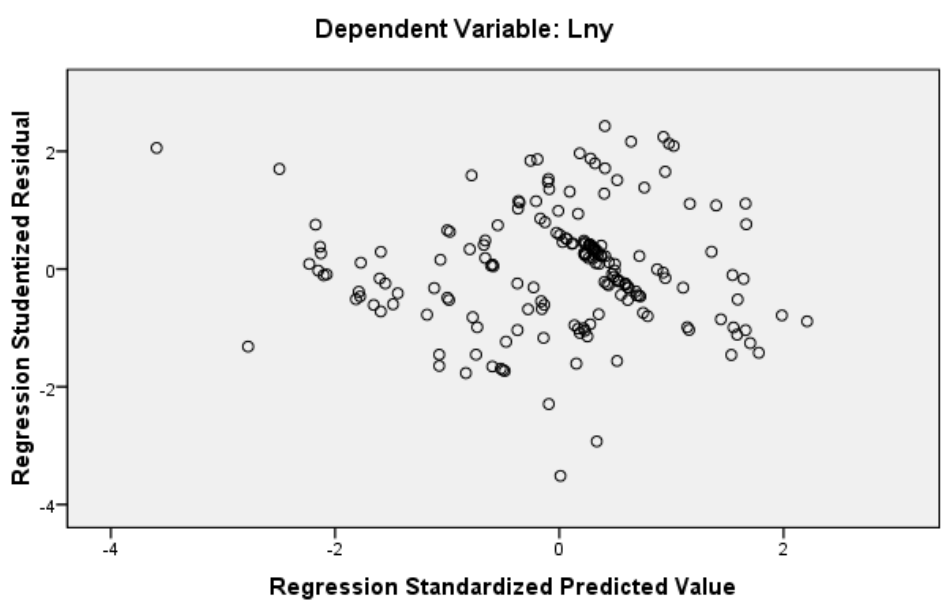

Gambar 3.4. Scatterplots log lin model 


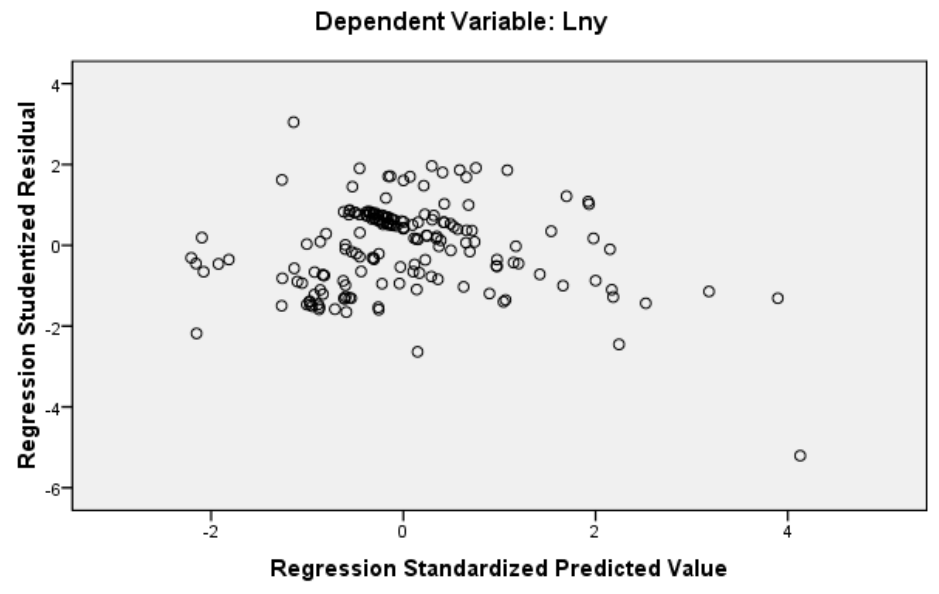

Gambar 3.6. Scatterplots log log model

Berdasarkan Gambar 3.2 s.d. Gambar 3.6. di atas terlihat titik-titik tidak membentuk pola yang jelas dan menyebar merata di atas dan di bawah angka 0 pada sumbu $Y$, artinya bahwa tidak terjadi heteroskedastisitas pada model regresi.

\subsection{Hasil Pemilihan Model}

Dari serangkaian uji statistik dan uji asumsi klasik maka ringkasan hasil pengujian dapat dilihat di Tabel 3.5.

Tabel 3.5. Ringkasan hasil nilai pengujian model nilai tanah

\begin{tabular}{|c|c|c|c|c|}
\hline Var & $\begin{array}{l}\text { Model } \\
\text { Lin-lin }\end{array}$ & $\begin{array}{c}\text { Model } \\
\text { Lin-Log }\end{array}$ & $\begin{array}{c}\text { Model } \\
\text { Log-Lin }\end{array}$ & $\begin{array}{c}\text { Model } \\
\text { Log- } \\
\text { Log }\end{array}$ \\
\hline Uji t parsial & 5 & 5 & 6 & 6 \\
\hline Uji F hitung & 7.676 & 14.816 & 8.024 & 27.464 \\
\hline Uji R2 & 0.329 & 0.504 & 0.34 & 0.66 \\
\hline $\begin{array}{c}\text { Uji } \\
\text { multikolinie } \\
\text { ritas }\end{array}$ & $\begin{array}{c}\mathrm{Me} \\
\text { menuhi }\end{array}$ & $\begin{array}{c}\mathrm{Me} \\
\text { menuhi }\end{array}$ & $\begin{array}{c}\mathrm{Me} \\
\text { menuhi }\end{array}$ & $\begin{array}{c}\mathrm{Me} \\
\text { menuhi }\end{array}$ \\
\hline $\begin{array}{c}\text { Uji } \\
\text { heteroskedas } \\
\text { tisitas }\end{array}$ & $\begin{array}{c}\text { Me } \\
\text { menuhi }\end{array}$ & $\begin{array}{c}\mathrm{Me} \\
\text { menuhi }\end{array}$ & $\begin{array}{c}\mathrm{Me} \\
\text { menuhi }\end{array}$ & $\begin{array}{c}\text { Me } \\
\text { menuhi }\end{array}$ \\
\hline
\end{tabular}

Dari pemilihan model yang telah dilakukan, model yang paling baik adalah model logaritma (log-log). Persamaan dari nilai tanah hasil pemilihan model adalah

$\mathrm{LnY}=23.081+0.271_{\mathrm{LnX} 1}$ (Jarak Bidang Terhadap CBD $)+0.238 \mathrm{LnX} 2$ (Jarak Bidang Terhadap Jalan Lokal Primer) $+0.229_{\text {LnX3 }}$ (Jarak Bidang Terhadap sungai) $+0.280_{\mathrm{LnX} 4}$ (Jarak Bidang Terhadap Puskesmas) $+0.223_{\mathrm{LnX5}}$ (Jarak Bidang Terhadap SD) +0.260 LnX6 (Jarak Bidang Terhadap Universitas/Akademi).

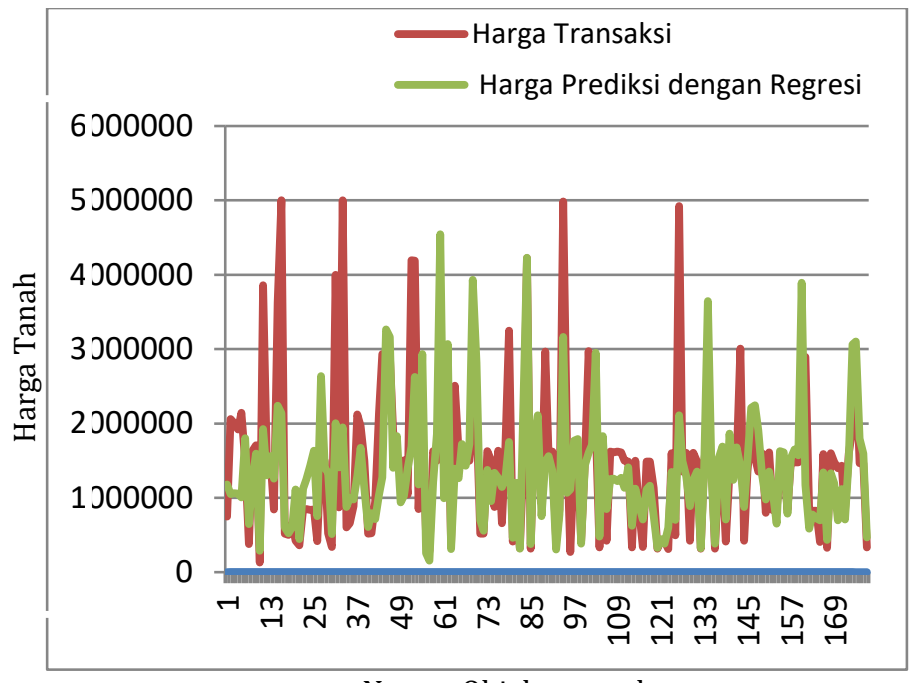

Nomer Objek sampel

Gambar 3.7. Perbandingan Nilai tanah prediksi dengan harga transaksi sampel

Hasil dari prediksi nilai tanah dengan metode Analytical Hierarchy Process dan Regresi dapat dilihat pada Gambar 3.7. Model terpilih dari hasil regresi selanjutnya dievaluasi dengan melakukan uji kualitas terhadap model tersebut. Uji kualitas model ini dilakukan dengan menghitung nilai koefisien variasi / COV (Coefficient of Variation) dan perbedaan harga prediksi / PRD (Price Related Differential).

$\operatorname{COV}=\frac{100 \sqrt{\Sigma}[(\hat{\mathrm{Y}} / \mathrm{Y})-\{(\hat{\mathrm{Y}} / \mathrm{Y}) / \mathrm{n}\}]^{2} /(\mathrm{n}-1)}{((\hat{\mathrm{Y}} / Y) / n)}$

$=0.030172667(3.017 \%)$ (dalam syarat yang ditentukan $<10 \%$ ) (Eckert, 1990)

$\mathrm{PRD}=\frac{\boldsymbol{\Sigma}\left(\frac{\hat{Y}}{\boldsymbol{Y}}\right) / \boldsymbol{n}}{\boldsymbol{\Sigma} \hat{\mathrm{Y}} / \boldsymbol{\Sigma} \boldsymbol{Y}}$

$\mathrm{PRD}=1.000907384$ \%) (dalam syarat yang ditentukan 0.98-1.03)

\section{Kesimpulan}

Berdasarkan hasil dan pembahasan, dapat disimpulkan bahwa hasil dari tingkat akurasi model nilai tanah dengan pendekatan metode AHP dan Regresi linier menunjukkan tingkat akurasi yang memuaskan dimana nilai COV sebesar $3.017 \%$ dan PRD sebesar 1.000907384. tetapi dari serangkaian uji pemilihan model nilai tanah masih terdapat beberapa faktor yang ternyata kurang memiliki pengaruh terhadap perubahan nilai tanah.

Nilai tanah yang dihasilkan dari penelitian ini secara umum dipandang lebih objektif jika dibandingkan penilaian tanah biasa(tanpa menggunakan metode AHP dan regresi Linier). Metode AHP dan Regresi ini dapat digunakan sebagai alternatif cara penilaian massal bagi 
pemerintah khususnya di Kecamatan Grogol Kabupaten Sukoharjo.

\section{Pernyataan Konflik Kepentingan}

Penulis menyatakan tidak ada konflik kepentingan dalam artikel ini (The authors declare no competing interest).

\section{Referensi}

Arifia, Dina. (2016). Pengaruh Perkembangan Kegiatan Perdagangan dan Jasa Terhadap Perubahan Penggunaan Lahan di Solo Baru. (Skripsi), Universitas Sebelas Maret, Surakarta.

Eckert, J.K. (1990). Property Appraisial and Essesment Administration, The International Association of Assessing Officers. Chicago: Illiois.

Hartono, Mudji. (2008). Penentuan Nilai Tanah dengan Analisis Spasial, AHP dan Regresi di Sekitar Wilayah Bancana Banjir Lumpur Kabupaten Sidoarjo. (Thesis), Institut Teknologi Bandung, Bandung.

Marimin. (2004). Teknik dan Aplikasi Pengambilan Keputusan Kriteria Majemuk. Jakarta: Grasindo.

Rusmanto, Budi. (2005). Analisis Proses Pemodelan Nilai Adjustment dari Faktor-faktor yang Berpengaruh Terhadap Nilai Jual Obyek Pajak Bumi. (Thesis), Institut Teknologi Bandung, Bandung.

Siregar, Tondi Nugraha. (2012). Perbandingan Aplikasi Metode Regresi Linier Berganda dan Jaringan Syaraf Tiruan Dalam Pembuatan Peta zona Nilai Tanah. (Skripsi), Institut Teknologi Bandung, Bandung.

Wilson, Bill, Schurle, Bryan, Taylor, Mykel, Featherstone, A., \& Ibendahl., G. (2014). Regression Estimates of Different Land Type Prices and Time Adjustments. Journal Of The Asfmra, 192-203.

Peraturan Presiden No 20 Tahun 2015 Tentang Badan Pertanahan Nasional, (2015) 